\title{
PREVENTION OF MAJOR ACCIDENTS OF MOBILE RISK SOURCES
}

\author{
Katarína Mäkká1,*, Katarína Kampová1, Jacek Dworzecki² \\ ${ }^{1}$ Faculty of Security Engineering, University of Zilina, Zilina, Slovakia \\ ${ }^{2}$ Faculty of Security Sciences, Military University of the Land Forces in Wroclaw, Wroclaw, Poland \\ *E-mail of corresponding author: katarina.makka@fbi.uniza.sk
}

\section{Resume}

At present, the issue of public safety in the production and manipulation of hazardous chemicals deserves more attention, since various major accidents such as fires, explosions and toxic gas releases take place frequently. The issue of prevention of emergency events has become more and more topical. The growing amount of hazardous substances transported leads to increased risk of emergencies. In order to reduce this risk in the transport of hazardous substances, a number of technical, operational, traffic and safety conditions and requirements must be fulfilled. These all contribute to the reduction of hazards and risks. The aim of the presented article was to determine the extent of the danger zone in the event of a gasoline leak due to a traffic accident in a built-up urban area with a high frequency of traffic and population movement.

\section{Article info}

Received 15 December 2020

Accepted 14 January 2021

Online 21 May 2021

\section{Keywords:}

dangerous goods, emergency accident, fuels, mobile risk source, prevention, road transport

\section{Introduction}

Dangerous substances and articles are those which, by their nature, properties or conditions, may endanger the safety of persons, animals or the environment. The road transport of these substances must be carried out in accordance with the European Agreement concerning the International Carriage of Dangerous Goods (ADR). Hazardous chemicals and their transport are a significant mobile source of risk, especially due to the difficult prediction of their occurrence [1]. The transport routes are planned with regard to the starting and destination point of transport, time requirements of the customer to perform the transport, legislative restrictions related to the choice of route and optimization of a vehicle operation and driver's work. An essential determinant is the economics of transport, which significantly influences the decision-making of entities involved in the transport process and can have a significant impact on the degree of risk in transport. In the case of mobile sources of chemicals, a hazardous area is created along the transport routes.

In this context, the issue of prevention of major accidents is developing dynamically. Major accidents are significant events in the life of a society in particular its effects on human health, property or the environment. To prevent such major industrial accidents, many developed countries, including the US and EU, have implemented emergency management systems ranging from accident prevention, emergency preparedness and emergency response to accident relief [2].

The issue of prevention of major accidents, associated with the release of hazardous substances, is becoming a much-discussed professional public worldwide. At present, attention is being paid to mobile sources of risk, which are increasing the number of accidents during the transport of dangerous goods, namely: assessing the risks of spent fuel transportation and storage [3], evaluation of the safety level of fuel transportation [4], quantitative risk analysis of life safety and financial loss for road accident of fuel cell vehicle [5].

\section{Analysis of the current situation in the field of security of fuel distribution}

Road traffic accidents with the consequent release of hazardous substances endanger people's lives, property and the environment worldwide. The prevention and control of these accidents is drawing a growing attention from the whole society [6]. Therefore, the issue of prevention of such events and the resulting application of preventive measures come first. The European Union seeks to regulate this environment and set rules for all the transport participants, i.e. sender, carrier and consignee, as well as for other participants (e.g. loading, packing, filling organization, tank container operator, etc.). One of these instruments is the European 


\section{Road freight transport of dangerous goods by type of goods, EU, 2018}

(\% share in tonne-kilometres)

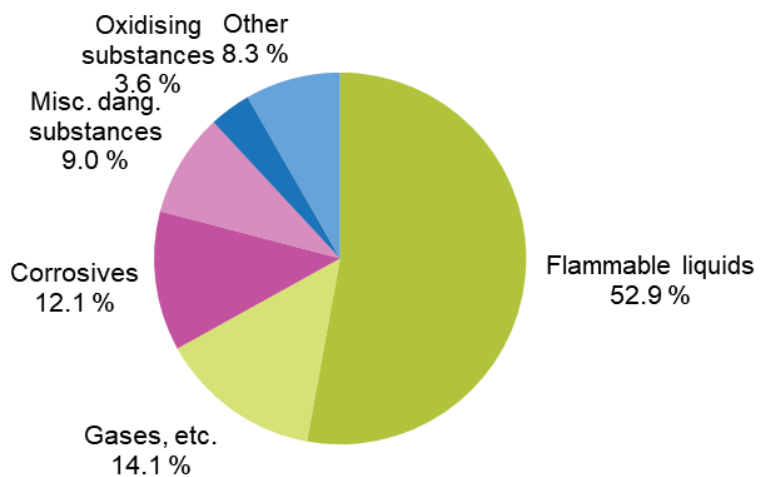

Note: Malta excluded (see chapter 'data sources'); Data for Luxembourg not available for 2018 Note: Confidential data for 'substances liable to cause infections' Source: Eurostat (online data code: road_go_ta_dg)

Figure 1 Road freight transport of dangerous goods by type of goods in Europe [10]

Agreement concerning the Transport of Dangerous Goods by Road (ADR), which was concluded on 30 September 1957 in Geneva under the auspices of the United Nations Economic Commission for Europe and entered into force on 29 January 1968, [7].

This Agreement was amended by the Protocol of Amendment to Article 14, paragraph 3, in New York on 21 August 1975, and entered into force on 19 April 1985, [8].

The ADR agreement has two technical annexes „Annex A and Annex B“.

Pursuant to Article 2 of the ADR, dangerous goods, which have been excluded from carriage pursuant to Annex A may not be accepted for international carriage, whereas the international carriage of other dangerous goods may be authorized only after completion of:

- the conditions set out below in Annex A for these dangerous goods, with a special focus on their packaging and labeling requirements;

- the conditions set out below in Annex B, with particular reference to the requirements of the construction, equipment and operation of vehicles transporting these dangerous goods.

Annexes A and B have been regularly revised on a two-year cycle since the entry into force of the ADR.

Currently, contracting parties to the ADR are: Albania, Andorra, Austria, Azerbaijan, Belgium, Belarus, Bosnia and Herzegovina, Bulgaria, Cyprus, Czech Republic, Croatia, Denmark, Estonia, Finland, France, Georgia, Germany, Greece, Hungary, Iceland, Ireland, Italy, Kazakhstan, Latvia, Liechtenstein, Lithuania, Luxembourg, Malta, Montenegro, Morocco, Netherlands, Nigeria, North Macedonia, Norway, Poland, Portugal, Republic of Moldova, Romania, Russian Federation, San Marino, Serbia, Slovakia, Slovenia, Spain, Sweden, Switzerland, Tajikistan, The Republic of Uzbekistan,
Tunisia, Turkey, Ukraine, United Kingdom of Great Britain and Northern Ireland.

Each Member State has adopted the ADR into its national law or has its own national rules. The $\mathrm{ADR}$ applies to transport operations carried out in the territory of at least two of the above Contracting Parties.

According Bernatik, the assessment of mobile risk sources is not yet prescribed by law in the European Union [9]. However, the transport of dangerous substances represents a particular hazard above all to the densely populated areas of urban zones, where releases of toxic or flammable substances into the air may endanger the health and/or lives of many inhabitants. To date, the evaluation of consequences of accidents from the mobile risk sources has been dealt with only haphazardly and not in detail.

\subsection{Quantities of dangerous goods transported in the EU in 2018}

Statistical data, directly related to the transport of dangerous goods, are available on the website of the European Statistical Office Eurostat. Between 2014 and 2018, most Member States of EU registered increase in transport of dangerous goods.

Figure 1 shows the types of dangerous goods in EU road freight transport in 2018. The largest specific productgroup was „flammable liquids“, taking over more than half of the total (52.9\%). Two other groups, „gases (com-pressed, liquefied or dissolved under pressure)“ and „corrosives“, accounted for $14.1 \%$ and $12.1 \%$ respectively.There were very small changes compared to previous years, the distribution between product groups remained quite similar over time. The above statistical data show that the largest group in terms of 
Table 1 Selected accidents of tankers

\begin{tabular}{lll}
\hline state & the cause of the accident & consequences \\
\hline Iran (2004) & accident of a tanker carrying 18,000 liters of petrol & $\begin{array}{l}\text { the explosion killed 200 people and injured } \\
100 \text { people }\end{array}$
\end{tabular}

Africa (2006) tank overturning and subsequent explosion

Nigeria (2007)

India (2007)

Iraq (2007)

Czech Republic (2007)

Slovak Republic (2018)

Italy (2018) traffic accident of a tanker transporting diesel

the 33,000-liter tank crashed and subsequently exploded

a jeep crashed into a diesel tank.

a fuel tank exploded near a gas station

the driver, for not identified reasons, went out of the way to the field

a tanker truck with petrol exploded after rearending a stopped truck the explosion killed 35 people who tried to pump petrol from a crashed tank

the explosion killed at least 89 people and injured about 100 people

eleven people died in the crash, four suffered serious injuries

the explosion killed at least 50 people and injured 60

leakage of 30,000 liters of diesel. the oil got into the groundwater and into the stream, which is located near the crash site

overturned the fully loaded tanker (30 000 liters of fuels), 33-year-old driver died

at least two people were killed, up to 70 injured and part of the raised expressway collapsed in the fireball transported amount are flammable liquids (up to $52.9 \%$ ) In the following text it is dealt with this specific group of hazardous substances.

\subsection{Examples of some emergency events in the transport of fuels by road in the world and in the Slovak Republic}

The most common causes of traffic accidents, according to long-term statistics from various countries, are:

- human in $85 \%$ of cases

- the traffic route is the primary cause in $10 \%$ of cases,

- the means of transport is a source of accidents in about $5 \%$ of cases.

There are often several factors involved in accidents

[1]. Although the competent authorities, carriers and drivers, pay the close attention to safety issues and compliance with the standards, rules and regulations laid down for the transport of road transport fuels, we are sometimes informed of accidents involving tanks carrying diesel, petrol or other dangerous substances. So far, accidents or incidents have occurred during the transport of petroleum products, which resulted in a vehicle fire, contamination of the surroundings with petroleum products, or groundwater contamination. The following accidents are well known (see Table 1).

An example of more recent accident in the transport of hazardous substances is the overturning and subsequent explosion of a tanker carrying 4,000 gallons of aviation fuel (15,000 liters). This event happened on February 20, 2020 in Indianapolis. The fire spread about 500 feet causing severe, catastrophic damage to the pavement and both sides of the bridge. The accident resulted in the death of the tanker driver.

A photo from the Indiana Department of Transportation (see Figure 2) shows wreckage after a fuel tanker overturned and caught fire at the intersection of interstates 70 and 465 on Indianapolis east side on Thursday, Feb. 20, 2020.

\section{Case study}

The aim of the case study is to determine the extent of the danger zone in the event of a gasoline leak in a built-up urban area with a high frequency of traffic and population movement. Examples of the abovementioned emergency events also prompted elaboration of a study focusing on urban development with a high concentration of inhabitants. The consequences of such events can cause injury or death to a large number of people.

In the Slovak Republic, fuels are the most often transported by road by the road tankers of a tractor with a semi-trailer [12]. Individual tank sets are multichamber (up to 6 separate chambers) with the possibility of transporting individual types of fuel at once, in different volumes, from 20,0001 up to 50,0001 .

For the purpose of the case study, an emergency 


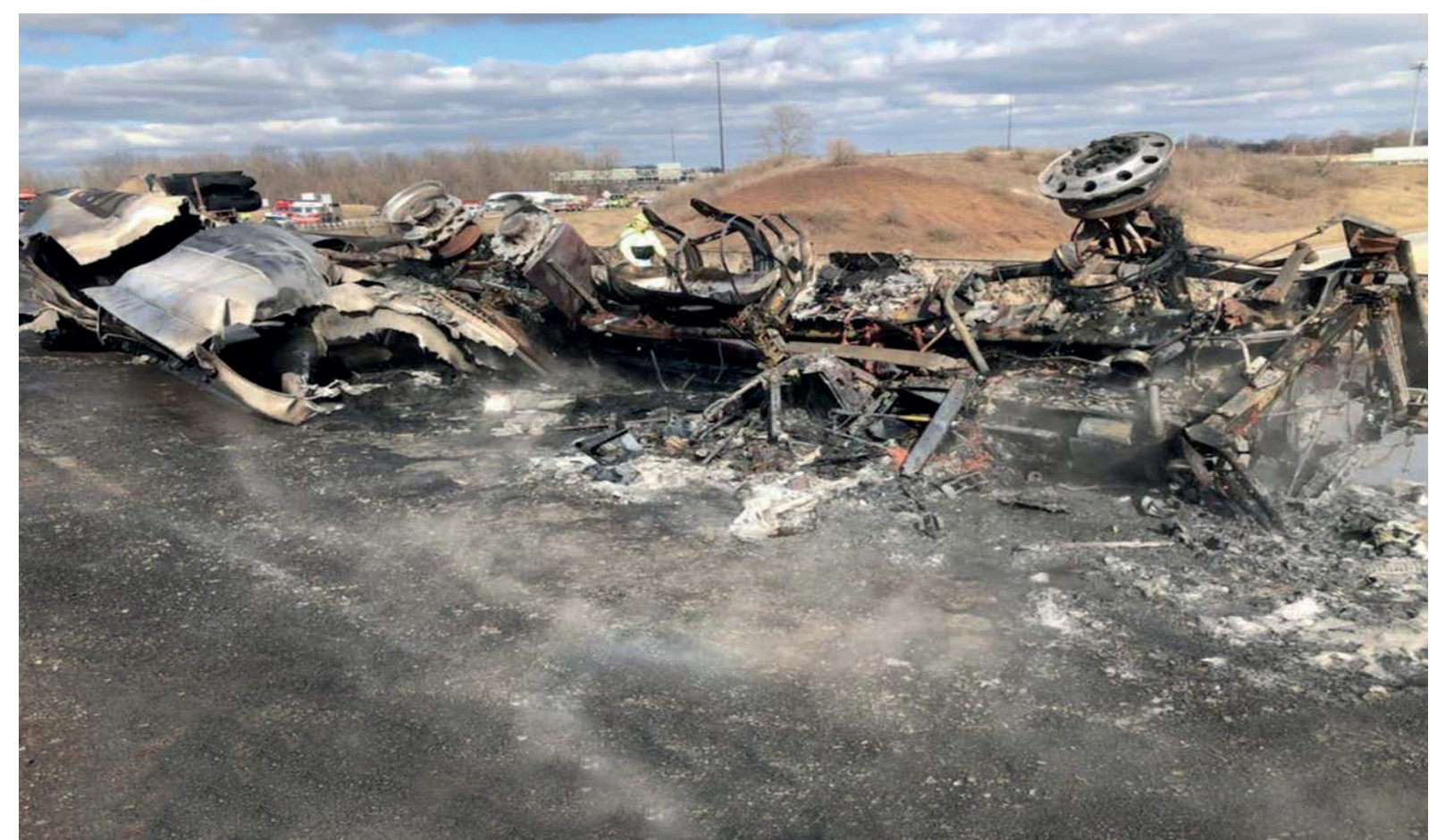

Figure 2 A tanker overturned and caught on fire in the intersection of I-465 and I-70 on Indianapolis' east side on Thursday, Feb. 20, 2020 [11]

Table 2 Survey of modeling results program TerEx

\begin{tabular}{llc}
\hline consequences of an emergency scenario & danger zones & (m) \\
\hline \multirow{2}{*}{ Pool fire } & first degree burns at a distance from the flame (m) & 118 \\
& failure of steel strength at a distance from the flame (m) & 15 \\
& $10 \%$ mortality from the tank & 68 \\
& $50 \%$ mortality from the tank & 58 \\
& & $19 / 37$ \\
Plume & danger to persons from direct cloud impact & $44.5 / 43.5$ \\
atmospheric stability D / F & serious damage to buildings & $66.5 / 57.5$ \\
& danger to persons outside the building from serious injuries & $124 / 94.5$ \\
& danger to persons through window glass & 99 \\
& & 479 \\
BLEVE (Boiling Liquid Expanding Vapor & maximum diameter of the fireball (m) & 259 \\
Explosion) & $10 \%$ mortality from the tank & 209 \\
& $50 \%$ mortality from the tank & 99 \\
\hline
\end{tabular}

scenario was modeled: during the transport of gasoline, the entire transported amount of gasoline leaked from the tank in a built-up urban area with a high frequency of traffic and population movement. Estimated population density at the accident site 160 persons/ha. Source of risk: tank with a volume of $46 \mathrm{~m}^{3}$, transported amount of petrol: $36,800 \mathrm{~kg}$.

Currently, there are many software products available that allow scenario building and risk assessment [13-14]. Software products are based on physical models, they allow to take into account the influence of working conditions, properties of leaking substances and environmental influences on the extent of damage and contamination, which not only speeds up the calculation but also refines the data obtained [15].

The simulation tools TerEx was chosen for the purpose of simulating the consequences of an emergency event connected with the leakage of transported fuels. 
The consequences of the emergency scenario were modeled in two representative types of weather conditions:

- normal air stability 4 th class $=\mathrm{D}$, medium wind speed - $5 \mathrm{~m} \cdot \mathrm{s}^{-1}$ (most common conditions during the year),

- $\quad$ very stable conditions 1 st class $=\mathrm{F}$, wind speed low - $1.7 \mathrm{~m} . \mathrm{s}^{-1}$ (worst dispersion, affected largest area the worst case scenario).

In the event of an emergency, associated with the leakage of the entire amount of gasoline from the tank, a risk for potential fatality would be for a person at a distance of $68 \mathrm{~m}$ from the crashed tank (see Table 2 ). The number of people at risk of an emergency was calculated from:

$\mathrm{N}=\mathrm{A} \cdot \mathrm{P}_{\mathrm{D}}$

where: „N" is the number of persons at risk, „A“ is the total affected area (affected area) [ha], " $\mathrm{P}_{\mathrm{D}}$ “ is the population density in the affected area [number of persons / ha].

Given the population density (160 inhabitants per hectar), 11.3 people will be potentially fatally injured. During the initiation and subsequent explosion of the escaped vapor cloud, the consequences of the explosion are worse in the case of atmospheric stability type F.

\subsection{Preventive measures implemented by the management of transport companies}

Transport and delivery of fuel to the customer requires compliance with international and national regulations, safety and especially the timeliness of delivery. This time pressure can cause non-compliance with the specified regulations at some stage of the fuel transport.This can ultimately lead to an emergency in the transport process and consequently endanger life, health, property and the environment. The rapid action can minimize the negative effects of emergencies and thus the degree of threat to the population in the vicinity of their occurrence.

One way to reduce the risks arising from the fuel distribution process is to comply with the prescribed operating and transport conditions, set by the ADR agreement by the participants in the transport process (i.e. consignor, transporter, consignee, vehicle manufacturer) and compliance with safety regulations when handling fuel (during the filling, dispensing fuel). However, even the best regulations will not prevent accidents and incidents in the road transport. It is only during the liquidation of traffic accidents that insufficient compliance with the above regulations is detected. Not enough attention is paid to:

- vehicle markings (incorrectly used or missing warning signs),
- the correct and accurate classification of the substance being transported in Class 3 ,

- vehicle equipment (prescribed mandatory equipment),

- permissible mass of the vehicle with fuel,

- readiness, professionalism and training of the driver transporting fuel.

According to an interview with an employee of a transport company that deals with the fuel transport, in the past, in the liquidation of traffic accidents or during the inspection activity, they were fully convinced that insufficient attention was paid to the above-mentioned important regulations, e.g. insufficient marking of consignments, missing warning signs and inscriptions of technical marking, inaccuracy in the classification of dangerous substances, poor storage conditions, deficiencies in the use of transport packaging.

If one discusses the accident in the transport of fuels, the most common cause of accidents is considered to be the human factor, namely:

- Inexperienced driver - insufficient control of the complexity and specificity of the liquid substances transport in tanks. Employers should therefore entrust the transport of fuel-trained drivers with sufficient experience,

- Driver fatigue caused by failure to observe the prescribed driving and rest times,

- Wrong declaration in the consignment note, which can make it difficult to deal with an emergency.

The driver's readiness to deal with an emergency, the assessment of the situation and the subsequent decision on appropriate measures, as well as their precise implementation, would ensure that the emergency would not cause extensive loss of life, health, property or the environment.

Based on a summary of the above causes of accidents, the conclusion was drawn that it is important for the fuel companies to employ drivers with many years of experience and experience in driving a tank. Driving a tank truck is an art. But even here the principle applies that the talent and courage alone are not enough. The art of safe and reliable driving with fuels is acquired through many years of practice and constant learning. Investing in drivers ${ }^{6}$ education and training pays off for the company. Although the training consists of final tests and examinations, this does not ensure that the tank driver will comply with the regulations.

All these findings and negative experiences from the past should lead the transport companies to improve transport services and increase safety of the fuel transport. It is therefore important to inform, educate the drivers and all the workers who handle hazardous materials, in the form of conferences, seminars and training. These are ways to avoid unnecessary damage, loss, endangerment of lives, environmental pollution or major disasters. 


\section{Conclusion}

The issue of the safe transport of fuels is currently becoming very disscussed worldwide. The aim of the presented article was to point out to the need to prevent major accidents of mobile sources of risks. The impuls for preparation of the case study were the recent emergency events associated with the leakage and subsequent explosion of transported flammable liquids in the densely populated areas of urban zones with a high concentration of population.

Based on the model calculations, the zones of danger to the population in the event of a leak of the transported flammable liquid substance were determined. Based on the simulation of selected emergency scenarios, it is possible to imagine the danger posed to the surroundings by a tank truck with petrol with a volume of $46 \mathrm{~m}^{3}$.

Therefore, the issue of prevention has recently come to the fore. Dangers associated with use of the fuel transport must be anticipated and identified in time, but, above all, through appropriate preventive and mitigation measures it is necessary to prevent their possible negative effects.

\section{Acknowledgment}

This paper is a result of the science project „VEGA 1/0173/21 Research of measures implemented by security managers in the organizations related to the occurrence and spread of COVID-19 and in other emergency situations“.

\section{References}

[1] MOZER, V., LOVECEK, T., VELAS, A., MAKOVICKA, L. Fire safety and security threats identification and elimination. Advanced Materials Research [onine]. 2014, 1001, p. 306-311. ISSN 1022-6680, eISSN 1662-8985. Available from: https://doi.org/10.4028/www.scientific.net/AMR.1001.306

[2] LEE, K., KWON, HM., CHO, S., KIM, J., MOON I. Improvements of safety management system in Korean chemical industry after a large chemical accident. Journal of Loss Prevention in the Process Industries [online]. 2016, 42, p. 6-13 [accessed 2020-05-19]. ISSN 0950-4230 Available from: https://doi.org/10.1016/j.jlp.2015.08.006

[3] MIRAE, Y., ROBBY, CH., BO, G. K., BELAL, A., JAEHYUN, H., SANGHOON, L., HYUN G. A software tool for integrated risk assessment of spent fuel transportation and storage. Nuclear Engineering and Technology [online]. 2017, 49, p. 721-733 [accessed 2020-05-18]. ISSN 1738-5733. Available from: https://doi.org/10.1016/j. net.2017.01.017

[4] ZHONGYANG, L., CHUNHUA, CH., SHENGPENG, Y., BIN, W., LIJUAN, H., JIN, W., YICAN, W. Safety evaluation of spent fuel road transportation based on weighted nearest neighbor method. Annals of Nuclear Energy [online]. 2019, 127, p. 412-418 [accessed 2020-05-22]. ISSN 0306-4549. Available from: https://doi. org/10.1016/j.anucene.2018.12.036

[5] SUN, K, LI, Z. Y. Quantitative risk analysis of life safety and financial loss for road accident of fuel cell vehicle. International Journal of Hydrogen Energy [online]. 2019, 44, p. 8791-8798 [accessed 2020-05-21]. ISSN 0360-3199. Available from: https://doi.org/10.1016/j.ijhydene.2018.10.065

[6] REHAK, D, SENOVSKY, P., HROMADA, M. LOVECEK, T. Complex approach to assessing resilience of critical infrastructure elements. International Journal of Critical Infrastructure Protection [online]. 2019, 25, p. 125-138 [accessed 2020-05-19]. ISSN 1874-5482. Available from: https:/www.sciencedirect.com/science/article/pii/ S1874548218301744

[7] United Nations. European Agreement concerning the Transport of Dangerous Goods by Road (ADR) [online] [accessed 2020-05-18]. 2019. eISBN 978-92-1-004891-0, p. 668. Available from https://www.adr.sk/dohodaadr-2019/.

[8] Council of Europe. Protocol of Amendment to Article 14, paragraph 3 of the European Agreement of 30 September 1957 concerning the International Carriage of Dangerous Goods by Road [online] [accessed 202005-18]. 1975. p. 3. Available from://oemmndcbldboiebfnladdacbdfmadadm/https://unece.org/DAM/trans/danger/ publi/adr/Protocole_e.pdf

[9] REHAK, D., BERNATIK, A., NOVOTNY, P. Preference risk assessment of hazardous substances road transportation. In: European Safety and Reliability Conference Safety and Reliability ESREL 2014: Methodology and Applications: proceedings. 2014. ISBN 978-1-138-02681-0, p. 1671-1676.

[10] Road freight transport of dangerous goods by type of goods in Europe [online] [accessed 2020-05-18]. Available from: https:// ec.europa.eu>eurostat>images

[11] A tanker overturned and caught on fire in the intersection of I-465 and I-70 on Indianapolis ${ }^{6}$ east side on Thursday, Feb. 20, 2020 [online] [accessed 2020-05-20]. Available from: https://eu.indystar.com/picture-gallery/ news/2020/02/20/jet-fuel-tanker-explodes-on-citys-east-side/4823811002 
[12] REHAK, D, SENOVSKY, P., HROMADA, M. LOVECEK, T., Novotny, P. Cascading impact assessment in a critical infrastructure system. International Journal of Critical Infrastructure Protection [online]. 2018, 22, p. 125-138 [accessed 2020-05-20]. ISSN 1874-5482. Available from: https:/www.sciencedirect.com/science/article/ pii/S1874548215300251

[13] RISTVEJ, J., ONDREJKA, R., SIMAK, L., LOVECEK, T., HOLLA, K., LACINAK, M., SURINOVA, L., JANOSIKOVA, M. Simulation technologies in risk prevention within crisis management. In: European Simulation and Modelling Conference ESM 2016 -Modelling and Simulation: proceedings. 2016. ISBN 978-90-77381-95-3, p. 327-330.

[14] SIVAKOVA, L., LOVECEK, T. Modelling and simulation of crisis phenomena as a new tool for research and training in visegrad countries. Key Engineering Materials [online]. 2017, 755, p. 346-352. ISSN 1662-9795. Available from: https://doi.org/10.4028/www.scientific.net/KEM.755.346

[15] JANTOSOVA, A., DOLNAK, I., DADO, M. An overview of vehicular ad hoc networks. In: 17th IEEE International Conference on Emerging eLearning Technologies and Applications ICETA 2019: proceedings. 2019. ISBN 978-1-7281-4967-7, p. 305-308. 